\title{
Knowledge, Attitude and Practice Regarding Hepatitis C Prevention among People of Rural Community, Lahore
}

\author{
Sumaira Ejaz and Hajra Sarwar* \\ Lahore School of Nursing, The University of Lahore, Pakistan \\ Received: April 21, 2018; Published: May 10, 2018 \\ *Corresponding author: Hajra Sarwar, Lahore School of Nursing, The University of Lahore, Lahore, Pakistan
}

\begin{abstract}
Introduction: Cardiovascular-disease (CVD) is the disease that is related to heart, blood and vessels. In Pakistan, prevalence data for the cardiovascular disease is sparse, and literature indicates that there is $30-40 \%$ of all deaths in Pakistan due to cardiovascular diseases Aziz et al.

Methods: This was descriptive cross-sectional study. Convenient sampling was used and data was analyzed by SPSS version 21.

Results: The findings of the research were good knowledge and (67\%) high responses of correct answer were smoking is risk factor of CVD. The attitudes were negative, (28\%) high correct response was "do exercise for good health". The practices were very poor regarding the risk-factors of cardiovascular diseases.

Conclusion: The knowledge of participants towards the risk factors of cardiovascular diseases was somehow better. The attitude was comparatively negative and practices were poor. No one was following regular exercises, dietary modifications, manage stress and smoking.
\end{abstract}

Keywords: Knowledge; Attitude, Practice; Cardiovascular diseases; Risk factors of cardiovascular diseases

\section{Introduction}

The Cardiovascular diseases (CVDs) are a group of disorders of the heart and blood vessels and they include coronary heart disease, cerebrovascular diseases, deep vein thrombosis and pulmonary embolism and some other disorders of heart (WHO, 2013). According to Texas Heart Institute (THI) the risk-factors for cardiovascular-diseases are groups into two major and minor contributing factors. Main risk factors are hypertension, cig smoking, high fat level, diabetes, obesity and physically inactive. The minor risk factors contain stress due to anxiety, sex-hormone intake, birth-control pills and alcohol drinking. Pagani et al. [1]. Cardiovascular diseases are the number one cause of death globally more people die annually (WHO, 2013). The WHO statistics indicate that CVD related deaths are seventeen million yearly, and this amount is gradually increasing up to twenty three million by the end of 2030 Kumar [2].

In Pakistan, cardiovascular diseases are also the leading cause of morbidity and mortality. Prevalence data for the Cardiovascular disease is less, thirty to forty percent of all deaths in Pakistan are the result of cardiovascular diseases Aziz et al. The women are not only the target of this disease but also included men. In literature the risk for cardiovascular diseases are equal both in men and women Mosca et al. Knowledge of risk factors of CVDs is crucial for every young and adult. As stated in a study, increase numbers of young adults have increased risk of developing cardiovascular diseases Gaziano et al.

In this study the major modifiable risk factors are tobacco smoking, physical inactivity, unhealthy dietary intake, high cholesterol and stress. According to study conducted in Peshawar, Pakistan showed there is less knowledge regarding risk factors of cardiovascular diseases, which are lack of physical activity, excessive sugar intake, obesity, family history and stress Zuhaid, Zahir, \&Diju, [3]. A study reported that Pakistani young adult students have high prevalence of shisha smoking Habibullah et al. [4]. Another modifiable risk factor is physical inactivity. The term physical inactivity is also called "sedentarism". It is the lack of physical activity (WHO, 2011). Eating fast food and carbonated drinks are also dangerous for health. In Pakistan, the prevalence of high cholesterol level is about twelve percent due to junk foods Sherin [5]. Stress is the minor risk factor. As stated by the Dr. Susan, stress is the strain and anxiety that occur due to physical factors those are not be in a stable rangeDr. Susan. 


\section{Research Questions}

Research Question 1: What kind of knowledge rural community have regarding modifiable risk factors of cardiovascular diseases?

Research Question 2: What kind of attitude rural community possess toward modifiable risk factors of cardiovascular diseases?

Research Question 3: What are the preventive practices of rural community toward modifiable risks factors of cardiovascular diseases?

\section{Aim of the study}

The purpose of the research was to assess the knowledge, attitude and practice regarding modifiable risk factors of cardiovascular diseases among adults in Hussain Abad community, Lahore

\section{Significance of the Study}

The significance of the research work is to give awareness about the modifiable risk factors of cardiovascular diseases. The benefit to the community is to reduce the burden of cardiovascular diseases. Lessen the morbidity and mortality rate. The results of this study could be used by other researchers for further research study. The benefit to adults is giving education and awareness of cardiovascular diseases and its risk factors. It might reduce the occurrence of disease to some extent in future.

\section{Literature Review}

According to WHO fact sheet (2017), cardiovascular-diseases are the top and foremost reason for death, annually most of the people die due to cardiovascular diseases than any other disease. Moreover, in 2015 millions of people die due to cardiovascular diseases that represents $31 \%$ of deaths (WHO, 2017). Kazakh population indicates that the prevalence of cardiovascular disease risk is high and level of knowledge is less Kulkayeva et al. At International level, many countries have major causes of deaths due to risk factors of cardiovascular diseases. In Malaysia most of deaths are due to coronary heart diseases and heart attacks and ratio is higher in women than men Ibrahim et al. [6].

In Middle East region, such as in Kuwait due to rapid changes in economic and due to lifestyle changes like smoking, obesity and diabetes the prevalence of cardiovascular diseases are very high Awadet al.[7]. Asians have very high prevalence of cardiovascular diseases. In India, cardiovascular diseases are high due to risk factors include unhealthy diet, physical inactivity and tobacco smoking Bhagyalaxmi et al.[8]. The Attitude of respondents of rural community are bad toward cardiovascular diseases. In Contrast with study of North-East coastMalaysia (2012), where higher proportion of positive attitude were due to awareness of healthy lifestyles Muhamad et al. [9]. Tobacco smoking is the common risk factor for cardiovascular diseases. In National Academies Press Council, exposure to smoking in adults causes increase risk of heart diseases approximately 25-30\% Council [10].

Another study conducted in Kuwait also represent that smoking is common risk factor of heart diseases Awadet al. [7].
A study in North Ireland related to knowledge of risk factors of cardiovascular diseases stated that inactivity in lifestyle is the factor of cardiovascular diseases $\mathrm{Al} \mathrm{Hamarneh}$ et al.[11]. In another study of Nepal respondents have lack of knowledge regarding physical inactivity which is the risk factors of cardiovascular diseases Vaidya et al. [12]. However, fruit and vegetables intake are very low in rural community. These are included in unhealthy diet. In Jordanian research respondents have lack of knowledge about healthy diet Mukattash et al. [13].

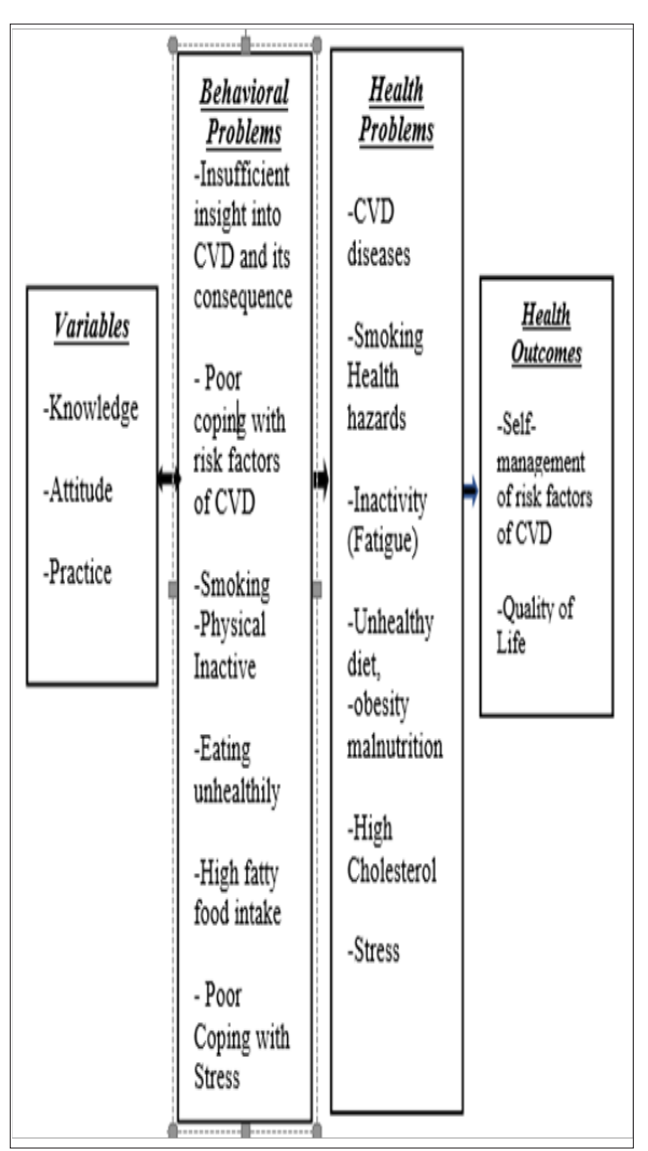

Figure 1: (PRECEDE) Model as a logic model for the needs assessment of self-managing CVD and its modifiable risk factors [6].

In addition, respondents take oily and fatty food excessively which causes the obesity and high cholesterol level. Stress is also an important risk factor for cardiovascular disease. The study conducted in Canada shows that the participants have less knowledge about stress Gill \& Chow [14]. Many respondents are associated with sedentary lifestyle, lack of exercise, poor diet, stress full life these factors are challenge for them to maintain healthy living Kulkayevaet al.(PRECEDE) Model as a logic model for the needs assessment of self-managing CVD and its modifiable risk factors Green \&Kreuter [15] (Figure 1). Thanks to all the community members. I am thankful to Ibrahim et al. [6], for giving me permission to use questionnaire. I am also thankful toSir Afsar Ali as a guide for me during this research. I am much thankful to the authority of University of Lahore for all cooperation to extend this study. 


\section{Methodology}

a. Setting: The research was conducted at Hussain Abad community.

b. Research Design: The research was descriptive crosssectional.

c. Population: People of Hussain Abad were the target population.

d. Sampling: Convenient sampling technique. The sample was 110 .

Research Instrument: An adopted questionnaire was used for this study to gather data and to answer the research questions Ibrahim et al. [6].

Data Gathering Procedure: A formal letter of approval was taken before starting the research. Verbal consent took from the participants.

Methods Used to Analyze Data: Data was analyzed by SPSS version 21.

Study Timeline: The study duration was September, 2017 to December, 2017.

Ethical Consideration: Ethical permission was obtained from Institutional Review-Board (IRB) of University of Lahore. At the household level, purpose of this study was explained to the respondents and verbal consent was taken before conducting the research.

\section{Results}

Table 1: Demographic related to Age, Gender, Education.

\begin{tabular}{|c|c|}
\hline Age & n (\%) \\
\hline $18-23$ & $19(17.3 \%)$ \\
\hline $24-29$ & $28(25.5 \%)$ \\
\hline $30-35$ & $36(32.7 \%)$ \\
\hline $36-40$ & $27(24.5 \%)$ \\
\hline \multicolumn{2}{|c|}{ Gender } \\
\hline Male & $33(30 \%)$ \\
\hline Female Marital Status \\
\hline Married & $77(70 \%)$ \\
\hline Unmarried & $23(74.5 \%)$ \\
\hline \multicolumn{2}{|c|}{ Education } \\
\hline
\end{tabular}

\begin{tabular}{|c|c|}
\hline Illiterate & $40(36.4 \%)$ \\
\hline Primary & $34(30.9 \%)$ \\
\hline Middle & $23(20.9 \%)$ \\
\hline
\end{tabular}

Socio-Demographics In demographic majority of were females $70 \%$ (77) and males 30\% (33) respectively with mean and standard deviation of $1.7 \pm 0.46$. The mean age of the participants was 28.5 years. $35 \%, 31 \%, 21 \%, 7 \%$, and $5 \%$ of respondents were illiterate, primary, middle, secondary and some others respectively (Table 1).

\section{Knowledge Regarding Cardiovascular Disease Risk Factors}

The items with higher results of correct replies were "Smoking is the risk factor of cardiovascular diseases" $(64 \%, 70)$ with mean and standard deviation of $1.13 \pm 0.59$. It is followed by "Cardiovasculardisease is related to heart and blood-vessels" $((60.9 \%, 67)$ with mean and standard deviation of 1.28 \pm 0.56 (Table 2).

Table 2: Knowledge Regarding CVD Risk Factors.

\begin{tabular}{|c|c|c|c|c|}
\hline $\begin{array}{l}\text { Sr. } \\
\text { No }\end{array}$ & Statements & $\begin{array}{l}\text { TRUE } \\
\text { n (\%) }\end{array}$ & $\begin{array}{l}\text { FALSE } \\
\text { n (\%) }\end{array}$ & $\begin{array}{l}\text { Don't } \\
\text { Know } \\
\text { n (\%) }\end{array}$ \\
\hline 1 & $\begin{array}{l}\text { Cardiovascular disease is } \\
\text { related to heart and blood } \\
\text { vessels }\end{array}$ & $67(60.9)$ & $37(33.6)$ & $6(5.5)$ \\
\hline 2 & $\begin{array}{l}\text { Most cardiovascular disease } \\
\text { cases are hereditary }\end{array}$ & $48(43.6)$ & $49(44.5)$ & 13(11.8) \\
\hline 3 & $\begin{array}{l}\text { CVD is the leading cause of } \\
\text { death }\end{array}$ & $48(43.6)$ & $35(31.8)$ & $27(24.5)$ \\
\hline 4 & $\begin{array}{l}\text { Cardiovascular disease is the } \\
\text { disease of women only }\end{array}$ & $31(28.2)$ & $67(58.2)$ & $15(13.6)$ \\
\hline 5 & CVD can occur to young people & $35(31.8)$ & $63(57.3)$ & $12(10.9)$ \\
\hline 6 & $\begin{array}{l}\text { Smoking is the risk factor of } \\
\text { cardiovascular disease }\end{array}$ & $70(63.6)$ & $27(24.5)$ & 13(11.8) \\
\hline 7 & $\begin{array}{l}\text { Doing house work as exercise } \\
\text { is enough for a day }\end{array}$ & $46(41.8)$ & $41(37.3)$ & $23(20.9)$ \\
\hline 8 & $\begin{array}{c}\text { If you have a slim body, you do } \\
\text { not need to exercise }\end{array}$ & $45(40.9)$ & $47(42.7)$ & $18(16.4)$ \\
\hline 9 & $\begin{array}{l}\text { Eating fruits or vegetables } \\
\text { is able to prevent from } \\
\text { cardiovascular diseases }\end{array}$ & $38(34.5)$ & $31(28.2)$ & $41(37.3)$ \\
\hline 10 & $\begin{array}{l}\text { Irregular eating patterns has } \\
\text { no harm on health }\end{array}$ & $45(40.9)$ & $46(41.8)$ & 19 (17) \\
\hline 11 & $\begin{array}{l}\text { High density lipoprotein (HLP) } \\
\text { is a good type of cholesterol }\end{array}$ & $40(36.4)$ & $32(29.1)$ & $38(34.5)$ \\
\hline 12 & $\begin{array}{c}\text { Prayer can help to reduce } \\
\text { stress }\end{array}$ & $64(58.2)$ & $19(17.3)$ & $27(24.5)$ \\
\hline
\end{tabular}

Table 3: Attitude Regarding Cardiovascular Diseases Risk Factors ( $\mathrm{n}=110)$.

\begin{tabular}{|c|c|c|c|c|c|c|}
\hline Sr No & Statements & $\begin{array}{c}\text { S D } \\
\text { n (\%) }\end{array}$ & $\begin{array}{c}\text { D } \\
\text { n }(\%)\end{array}$ & $\begin{array}{c}\text { U } \\
\text { n (\%) }\end{array}$ & $\begin{array}{c}\text { A } \\
\text { n }(\%)\end{array}$ & $\begin{array}{c}\text { S A } \\
\text { n (\%) }\end{array}$ \\
\hline 1 & Smoking is bad for health & $30(27.3)$ & $23(20.9)$ & $13(11.8)$ & $18(16.4)$ & $26(23.6)$ \\
\hline 2 & Do exercise to maintain healthy life style & $3(2.7)$ & $31(28.2)$ & $20(18.2)$ & $32(29.1)$ & $24(21.8)$ \\
\hline
\end{tabular}




\begin{tabular}{|c|c|c|c|c|c|c|}
\hline 3 & Prefer to play with laptop instead of doing exercise & $18(16.4)$ & $21(19.1)$ & $42(38.2)$ & $22(20)$ & $7(6.4)$ \\
\hline 4 & Walking a lot can give benefits to my health & $5(4.5)$ & $34(30.9)$ & $27(24.5)$ & $35(31.8)$ & $9(8.2)$ \\
\hline 5 & $\begin{array}{l}\text { Take fruits or vegetables in diet for maintaining } \\
\text { health }\end{array}$ & $10(9.1)$ & $24(21.8)$ & $11(10)$ & $49(44.5)$ & $16(14.5)$ \\
\hline 6 & Avoid drinking carbonated drinks & $13(11.8)$ & $25(22.7)$ & $43(39.1)$ & $11(10)$ & $18(64.4)$ \\
\hline 7 & Sometime eating super late at night is good & $12(10.9)$ & $26(23.6)$ & $16(14.5)$ & $44(40)$ & $12(109)$ \\
\hline 8 & Take less oily food for healthy lifestyle & $13(11.8)$ & $28(25.5)$ & 15 (13.6) & $36(32.7)$ & $18(16.4)$ \\
\hline 9 & Controlling stress can avoid to getting any disease & 15 (13.6) & 30 (27.3) & $21(19.1)$ & $33(30)$ & $11(10)$ \\
\hline 10 & I can manage my stress & $13(11.8)$ & $14(12.7)$ & $52(47.3)$ & $18(16.4)$ & $13(11.8)$ \\
\hline
\end{tabular}

\section{Attitude Regarding Cardiovascular-Disease Factors}

The answer with positive attitude was not accurately correct. However, the answer which was nearly correct was "Do exercise to maintain healthy life style" $(28 \%, 32)$ with mean and standard deviation of $3.3 \pm 1.18$. While, "Choose to use laptop but not prefer exercise" $(16 \%, 18)$ other one is "Sometime eating super late at night is good" $(11 \%, 13)$ the correct answer was Strongly Disagree. Result showed that respondents had negative attitude toward risk factors of cardiovascular diseases (Table 3).
Practices Regarding Cardiovascular Disease Risk Factors

In this study only $5 \%$ (5) respondents do exercise for 10 minutes daily. The $21 \%$ (24) respondents never eat fast food. Despite that, $37 \%$ (41) respondents do vigorous activity e.g. heavy lifting with mean and standard deviation of 3.0 \pm 0.82 . Majority of respondents had poor practices toward risk factors of cardiovascular diseases (Table 4).

Table 4: Practices Regarding Cardiovascular Diseases Risk Factors $(n=110)$.

\begin{tabular}{|c|c|c|c|c|c|}
\hline Sr No & Statements & $\begin{array}{l}\text { Always } \\
n=(\%)\end{array}$ & $\begin{array}{l}\text { Frequently } \\
\qquad \mathrm{n}=(\%)\end{array}$ & $\begin{array}{l}\text { Seldom } \\
n=(\%)\end{array}$ & $\begin{array}{l}\text { Never } \\
\mathrm{n}=(\%)\end{array}$ \\
\hline 1 & How often do you smoke? & $\begin{array}{c}33 \\
(30)\end{array}$ & $\begin{array}{c}18 \\
(16.4)\end{array}$ & $\begin{array}{c}7 \\
(6.4) \\
\end{array}$ & $52(47.3)$ \\
\hline 2 & $\begin{array}{l}\text { Does your daily activity involve } \\
\text { vigorous activity? }\end{array}$ & $\begin{array}{c}2 \\
(1.8)\end{array}$ & $\begin{array}{c}27 \\
(24.5)\end{array}$ & $41(37.3)$ & $40(36.4)$ \\
\hline 3 & Do you walk for 10 minutes daily? & $5(4.5 \%)$ & $17(15.5)$ & $57(51.8)$ & $31(28.2)$ \\
\hline 4 & $\begin{array}{c}\text { Do you spend your leisure time to } \\
\text { exercise at least } 20 \text { minutes? }\end{array}$ & $9(8.2)$ & 25 (22.7) & $36(32.7)$ & $40(36.4)$ \\
\hline 5 & $\begin{array}{l}\text { How often do you take fruits in your } \\
\text { diet? }\end{array}$ & $22(20)$ & $22(20)$ & $46(41.8)$ & $20(18.2)$ \\
\hline 6 & $\begin{array}{l}\text { How often do you take vegetables in } \\
\text { your diet? }\end{array}$ & $46(41.8)$ & $24(21.8)$ & $20(18.2)$ & $20(18.2)$ \\
\hline 7 & How often do you eat fast food? & $10(9.1)$ & $26(23.6)$ & $50(45.5)$ & $24(21.8)$ \\
\hline 8 & $\begin{array}{l}\text { Do you like to eat in between main } \\
\text { meals? e.g snaking }\end{array}$ & $8(7.3)$ & $25(22.7)$ & 39 (35.5) & $38(34.5)$ \\
\hline 9 & $\begin{array}{l}\text { Do you eat fried food as your main } \\
\text { course? }\end{array}$ & 11 (10) & $23(20)$ & $51(46.4)$ & $25(22.7)$ \\
\hline 10 & Do you lead a stressful life? & $35(31.8)$ & $27(24.5)$ & $24(21.8)$ & $24(21.8)$ \\
\hline
\end{tabular}

\section{Discussion}

Results showed that cardiovascular are the top and foremost reason for death in Pakistan. CVD history included topped the list hypertension, diabetes, heart attack and stroke O'Donnell et al. [16]. There was a high possibility of occurrence of cardiovascular diseases due to hereditary but mostly due to behavior changes and sedentary styles Khadeeja. Respondents had better knowledge that smoking is risk factor of cardiovascular diseases. In another study, secondhand exposure to smoke causes heart diseases, which increases the risk of disease by approximately 25-30\% Pope III et al. [17]. Moreover, the participants showed lower knowledge related to physical inactivity as risk factors when compared with study conducted in Iran Mazloomy et al. [18].

Eating fresh fruits and vegetables keeps your heart healthy. Less intake of fibers contributes to $20.0 \%$ of heart diseases in universe. Fruit and vegetables comprises some elements that defend against cardiac diseases, stroke and hypertension Rosamond et al. [19]. The relationship between stress and cardiovascular disease is not clear. Stress is a risk factor of cardiovascular diseases. It was identified by $64 \%$ of respondents, which is close to that study reported Jordan Mukattash et al. [13]. The study findings showed that approximately more than half of the participants assumed that they cannot reduce 
their stress. Stress-management plays a vital role in controlling the different factors of cardiovascular diseases Nekoueiet al. [20].

\section{Limitations}

This research had few limitations. First, the sample was convenient, which limited the generalizability of results to the population. In this study, women were unintentionally oversampled $(70 \%)$ because they were more likely to be available in the house when visited the home.

\section{Conclusion}

The study suggests that, level of knowledge regarding CVD is high in the rural community of Lahore, but there is no relation with the attitude and practices. The community people have negative attitude due to which practices are very poor.

\section{References}

1. Pagani F, Milano C, Tatooles A, Bhat G, Slaughter M,Birks E (2015) HeartWare HVAD for the treatment of patients with advanced heart failure ineligible for cardiac transplantation: results of the ENDURANCE destination therapy trial. J Heart Lung Transplant 34(4 Suppl): S9.

2. Kumar S (2017) Cardiovascular Disease and Its Determinants: Public Health Issue. Journal of Clinical Medicine and Therapeutics. J Clin Med Ther 2: 1 .

3. Zuhaid M, Zahir K K, Diju IU (2012) Knowledge and perceptions of diabetes in urban and semi urban population of Peshawar, Pakistan. J Ayub Med Coll Abbottabad 24(1): 105-108.

4. Habibullah S, Ashraf J, Javed R, Naz S, Arain GM,Akhtar T (2013) Prevalence of shisha smoking in College, University and Madarsa Students aged 20-25 years in Pakistan. Pakistan Journal of Medical Research 52(1): 3.

5. Sherin A (2014) Obesity: how to prevent Pakistani people from getting heavier? Khyber Medical University Journal 5(2): 59-60.

6. Ibrahim MM, Rahman NAA, Rahman NIA,Haque M (2016) Knowledge, Attitude and Practice of Malaysian Public University Students on Risk Factors for Cardiovascular Diseases. Journal of Applied Pharmaceutical Science Vol. 6 (02): 56-63.

7. Awad A, Al Nafisi H (2014) Public knowledge of cardiovascular disease and its risk factors in Kuwait: a cross-sectional survey. BMC Public Health 14(1): 1131.

8. Bhagyalaxmi A, Atul T, Shikha J (2013) Prevalence of risk factors of noncommunicable diseases in a District of Gujarat, India. J health, popul nutr 31(1): 78.

This work is licensed under Creative Commons Attribution 4.0 License

Submission Link: https://biomedres.us/submit-manuscript.php
9. Muhamad R, Yahya R,Yusoff HM (2012) Knowledge, attitude and practice on cardiovascular disease among women in North-Eastcoast Malaysia. International Journal of Collaborative Research on Internal Medicine \& Public Health.

10. Council NR (2010) Secondhand smoke exposure and cardiovascular effects: making sense of the evidence: The National Academies Press Washington, DC, USA.

11. Al Hamarneh YN, Crealey GE, Mc Elnay JC (2011) Coronary heart disease: health knowledge and behaviour. International journal of clinical pharmacy 33(1): 111-123.

12. Vaidya A, Aryal UR, Krettek A (2013) Cardiovascular health knowledge, attitude and practice/behaviour in an urbanising community of Nepal: a population-based cross-sectional study from Jhaukhel-Duwakot Health Demographic Surveillance Site. BMJ open 3(10): e002976.

13. Mukattash TL, Shara M, Jarab AS, Al-Azzam SI, AlmaaytahA,Al Hamarneh YN (2012) Public knowledge and awareness of cardiovascular disease and its risk factors: a cross-sectional study of 1000 Jordanians. International Journal of Pharmacy Practice 20(6): 367-376.

14. Gill R, Chow CM (2010) Knowledge of heart disease and stroke among cardiology inpatients and outpatients in a Canadian inner-city urban hospital. Canadian Journal of Cardiology 26(10): 537-541.

15.Green LW, Kreuter MW (1993) Health promotion planning: An educational and ecological approach: McGraw-Hill.

16. O’Donnell MJ, Xavier D, Liu L, Zhang H, Chin SL, et al. (2010) Risk factors for ischaemic and intracerebral haemorrhagic stroke in 22 countries (the INTERSTROKE study): a case-control study. The Lancet 376(9735): 112-123.

17. Pope CA, Burnett RT,Turner MC, Cohen A, Krewski D, et al. (2011) Lung cancer and cardiovascular disease mortality associated with ambient air pollution and cigarette smoke: shape of the exposure-response relationships. Environmental health perspectives 119(11): 1616.

18. Mazloomy SS, Baghianimoghadam $\mathrm{MH}$, Ehrampoush $\mathrm{MH}_{\text {, }}$ Baghianimoghadam B, Mazidi M,et al. (2014) A study of the knowledge, attitudes, and practices (KAP) of the women referred to health centers for cardiovascular disease (CVDs) and their risk factors. Health care for women international 35(1): 50-59.

19. Rosamond W, Flegal K, FridayG, Furie K, Go A, et al. (2007) Heart disease and stroke statistics-2007 update. Circulation 115(5): e69-e171.

20. Nekouei ZK, Yousefy A, Doost HTN, Manshaee G,Sadeghei M (2014) Structural Model of psychological risk and protective factors affecting on quality of life in patients with coronary heart disease: A psychocardiology model. J Res Med Sci 19(2): 90-98.

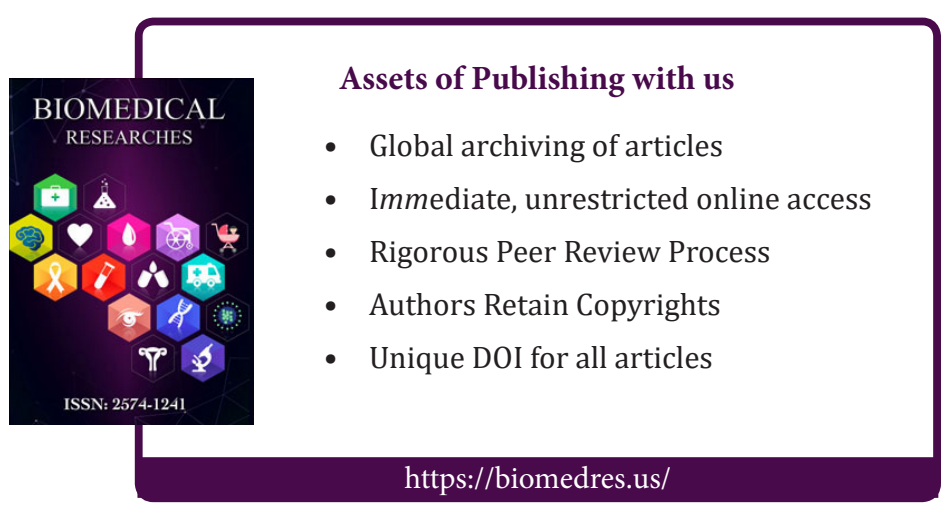

